\title{
Environmental Flows Risk Assessment of Effluent Outfalls from Conventional Wet Washed Coffee Refineries in Limu Kosa District of Southwestern Ethiopia
}

\author{
Tadesse Mosissa ${ }^{1,}$, , Bayu Dume ${ }^{1}$, Dechassa Tegegne ${ }^{2}$, Moti Yohannes² \\ ${ }^{1}$ Department of Natural Resource Management, College of Agriculture \& Veterinary Medicine, Jimma University, Jimma, Ethiopia \\ ${ }^{2}$ Department of Microbiology and Public Health, School of Veterinary Medicine, Jimma University, Jimma, Ethiopia
}

\section{Email address:}

tadesse88@gmail.com (T. Mosissa),dumebayu@gmail.com (B. Dume), dachassat@yahoo.com (D. Tegegne),

mygemechu@yahoo.com (M. Yohannes)

${ }^{*}$ Corresponding author

To cite this article:

Tadesse Mosissa, Bayu Dume, Dechassa Tegegne, Moti Yohannes. Environmental Flows Risk Assessment of Effluent Outfalls from Conventional Wet Washed Coffee Refineries in Limu Kosa District of Southwestern Ethiopia. American Journal of Environmental Protection. Vol. 5, No. 6, 2016, pp. 199-207. doi: 10.11648/j.ajep.20160506.17

Received: June 15, 2016; Accepted: July 5, 2016; Published: January 21, 2017

\begin{abstract}
The objective of this study was to assess the effects of recurrent effluent outfall from conventional wet washed coffee refineries (CWCR) on environmental flows (Eflows) based on the physicochemical parameters \& benthos assemblages as biological indicators. The experiment was done using complete randomized design (CRD) with 3 composite replicates at each 24 sampling sites of 4 river water basins. Six sampling sites were selected for physico-chemical \& 2 sampling sites were selected for benthos assemblages samples along each 4 river basin. Data analyses were performed by different statistical analyses such as analysis of variance (ANOVA) using SAS 9.2 and Minitab 16.0 software. Results of physicochemical parameters with biological revealed that there is highly significant effect between 4 Eflows \& among 24 sites at $(p<0.05)$. Characteristics of effluent outfall from CWCR has a BOD of up to $2993 \mathrm{mg} / \mathrm{L}$ and a COD of up to $2867 \mathrm{mg} / \mathrm{L}$ as well as the acidity of $\mathrm{pH}$ below 3 . These results can lead to depletion of $\mathrm{DO}$ and a decrease in $\mathrm{pH}$ (due to fermentation of organic matter) may hamper the sustainability of water bodies, which can kill off virtually all aquatic life. Except $\mathrm{pH}$ and DO, the other physico-chemical parameters exhibited that they were negative correlation with benthos assemblages. The results suggest that Eflows status of $\mathrm{DS}_{2}$ were depredation by effluent outfall from the conventional wet coffee refineries as compared to UPS. Therefore, face urgent intervention in the area of coffee refinery for effluent management and well designed treatment technologies (lagoons) for coffee waste treatment is highly recommended.
\end{abstract}

Keywords: Assimilation Capacity, Benthos, Coffee Refinery, Lagoon, Pulp, Riverbank, Ecohydrological

\section{Introduction}

Southwestern Ethiopia is a major and famous coffee growing region in Ethiopia [1]. There are two ways, by which coffee can be processed: wet and dry coffee refineries. Waste products are generated from both methods. In the study, sites there were two types of wet coffee refineries. These are modern or advanced and conventional wet washed coffee refineries (CWCR). The modern or advanced are subjected to mechanical removal of the parchment layer from the bean and the CWCR are biological (anaerobic) which is simply dumping it into the river bank [1-2].
Most of the coffee producers of the Limu Kosa District of Southwestern Ethiopia have been reported to follow conventional wet washed method. Approximately $80 \%$ of coffee harvest from the southwestern part of Ethiopia is processed by the CWCR [1]. This method has been described as the cheapest of coffee refineries. Most of these CWCR are constructed along the river bank located nearby, because it uses large amount of water during various stages of coffee production and processing [3-4]. The quantity of water used and the volume of wastewater generated from 
each CWCR vary from one another depending upon the process adopted and technology applied. The volume of water required for CWCR has been reported as 3240 Liters per bags per 850 gallon per bags of green coffee [4]. The major problem is during the CWCR peak time, the quantity of water used is too great for the size of the tanks and overflow of effluents instantly discharge it into river water body nearby is a common occurrence. Consequently, the amount of wastewater generated is high. If $100 \%$ of coffee producers use this method it generates a $36 \mathrm{BM}^{3}$ of wastewater [5]. It has been estimated that more than $45 \mathrm{~L}$ of wastewater is produced per kilogram of coffee processed. This results in pollution equivalent to $45 \mathrm{~kg}$ COD or $273 \mathrm{~m}^{3}$ of crude domestic sewage per day [6-7]. Obviously, CWCR requires a high degree of processing know-how and produces large amounts of effluents which have the potential to damage the Eflows [8]. Pollution of water resources can thus aggravate water scarcity [9]. These intensification of CWCR has therefore resulted in enormous volumes of rampant effluent discharges it into Eflows of households livelihood located nearby and become main threat to the surface and ground water qualities [3]. Although this fact is widely recognized, Eflows systems are the primary dump areas for disposal of effluents from coffee refineries containing wide varieties of synthetic and organic wastes. This variety of synthetic and organic wastes contains high acidic, nutrient, suspended and dissolved organic matter which makes it amenable to rapid biodegradation [3]. Due to this, river water body nearby these refineries is highly contaminated. Bad smell is common around the environment where CWCR existed. Currently, CWCR constitute a source of serious contamination. Therefore, there is a high risk to ecohydrological system services provision and household's livelihood (agricultural production, livestock, public health, and welfare). The disposal of effluent from conventional wet coffee refineries on pasture and agricultural land used to help as fertilizing the soil have been result in high acidification, water logging and anoxia. Due to this, different crops such as onion, tomato, potatoes, sorghum and maize had highly affected by quality and quantity $[4,10]$.

In spite of a generally good understanding of effect of effluent outfalls from CWCR, there is no innovation lab for effect of effluent generated from CWCR on the Eflows technology across the southwestern Ethiopia. Although, there is no consistent, reliable inventory, well studied and documented information with regarding to this area. Laboratory bioassays and chemical analysis of effluents policy is a new and only recently introduced and lacks in-depth studies. The intervention is not well supported by comprehensive research and thus there is gap of knowledge in the area. To fill the knowledge gap, the researcher tries to rigorously examine the problems and economic viability of effects of recurrent effluent outfall from CWCR towards livelihood improvement. Therefore, this research study aim was to assess the past, present $\&$ future trends of effects of recurrent effluent outfall from CWCR on Eflows of household's livelihood based on the physicochemical parameters and benthos assemblages as biological indicators in Limu Kosa district of southwestern Ethiopia. Consequently, the second objective of this research was to evaluate the capacity of coffee wastewater treatment performance of the conventional lagoon pond (traditionally waste stabilization ponds) before disposed into Eflows (socio-ecohydrological system services provision).

\section{Materials and Methods}

\subsection{Descriptions of the Study Area}

The study was conducted in Limu Kosa District of Jimma Zone, Southwestern Ethiopia (Figure 1). Limu Kosa District is located $420 \mathrm{~km}$ Southwest of Addis Ababa, the capital city of Ethiopia, lying between Latitude of $7^{\circ} 50$ and $8^{\circ} 6^{\prime}$ North and Longitude of $36^{\circ} 44^{\prime}$ and $37^{\circ} 29^{\prime}$ East. The altitude of the District ranges from $1200 \mathrm{~m}$ to $3020 \mathrm{~m}$ above sea level. It has an area of $2770.5 \mathrm{~km}^{2}$. Gibe, Awetu, Kebena, Ketalenca, Bonke and Dembi were found in the Limu Kosa District (data from the Limu Kosa District Agricultural and Rural Development Office).

\subsection{Methods}

\subsubsection{Experimental Design of the Study and Selection of Sampling Sites}

The experiment was done using complete randomized design (CRD) via 3 composite replicates at each 24 sampling sites of 4 river water basins to minimize their variations. From one river basin, six sampling sites were selected for physico-chemical and two sampling sites were selected for benthos assemblages. At each sampling site, 3 samples were collected cross sectionally (two corners and one center). These sites were upstream site (UPS), influent (INF), effluent (EFF), entry point (ENP), downstream one $\left(\mathrm{DS}_{1}\right)$ and downstream two $\left(\mathrm{DS}_{2}\right)$. UPS was used as control sites without any effects from the effluent because of their sites. Influent (INF) was the point at which wastewater enters the lagoons (treatment plants). Effluent (EFF) is wastewater leaving from the lagoon but before it enter the Eflows. Entry point (ENP) as highly impacted that was located after the EFF and it was the point at which lagoon effluent enters the Eflows. The distance between UPS, ENP, $\mathrm{DS}_{1}$ and $\mathrm{DS}_{2}$ was set at an interval of $500 \mathrm{~m}$. Downstream one $\left(\mathrm{DS}_{1}\right)$ was located at 500 meters below of ENP. Downstream two $\left(\mathrm{DS}_{2}\right)$ was located 500 meters below of $\mathrm{DS}_{1}$. In addition, samples were taken from INF and EFF, no actual distance determined because it depends on the coffee refineries designed. Specially, these wastewater samples were collected at the peak hour of coffee refineries for three days of a week from the chosen sampling points (figure 2) [3, 11, 12]. 


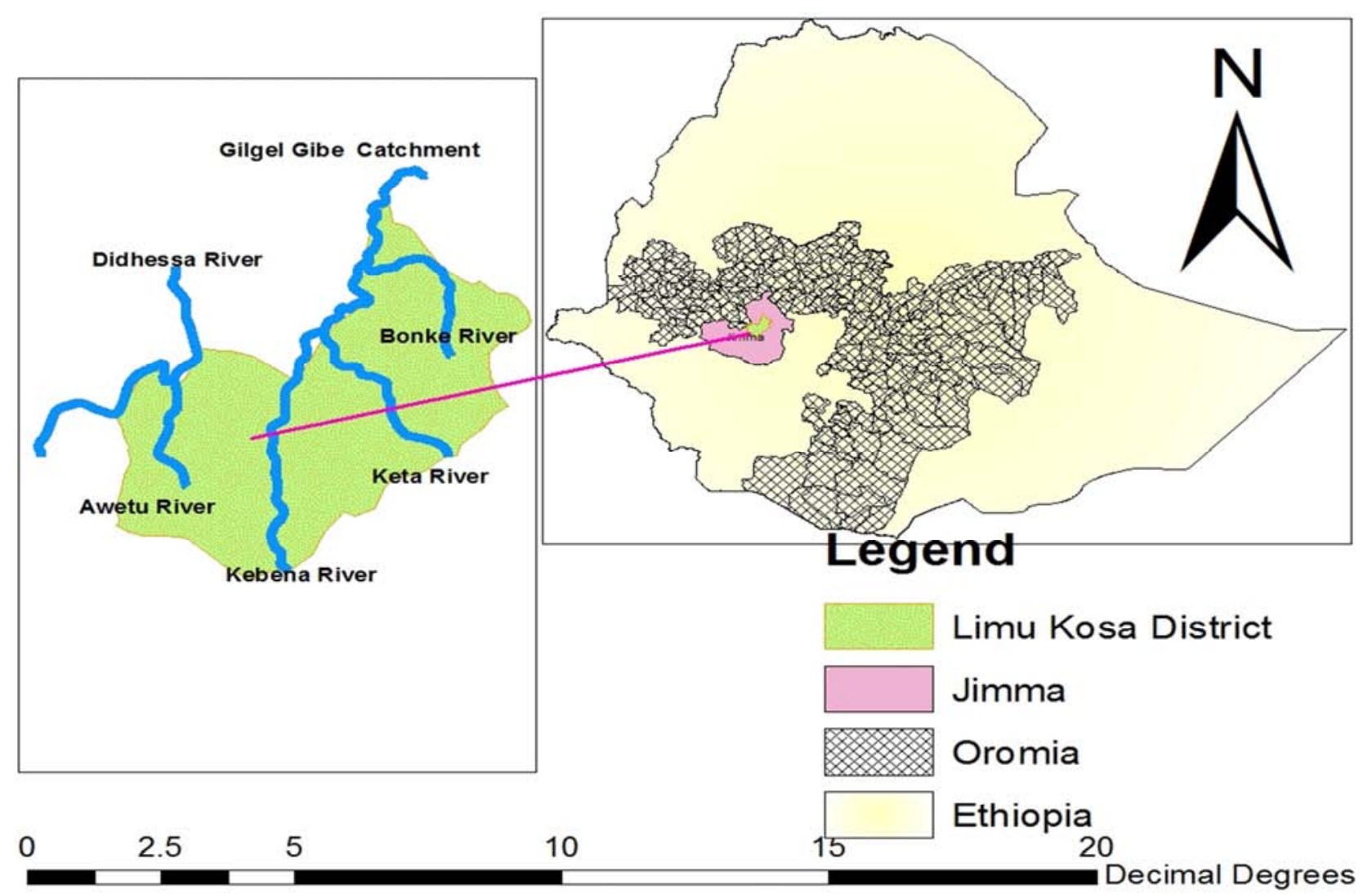

Figure 1. Map of the study sample site area.

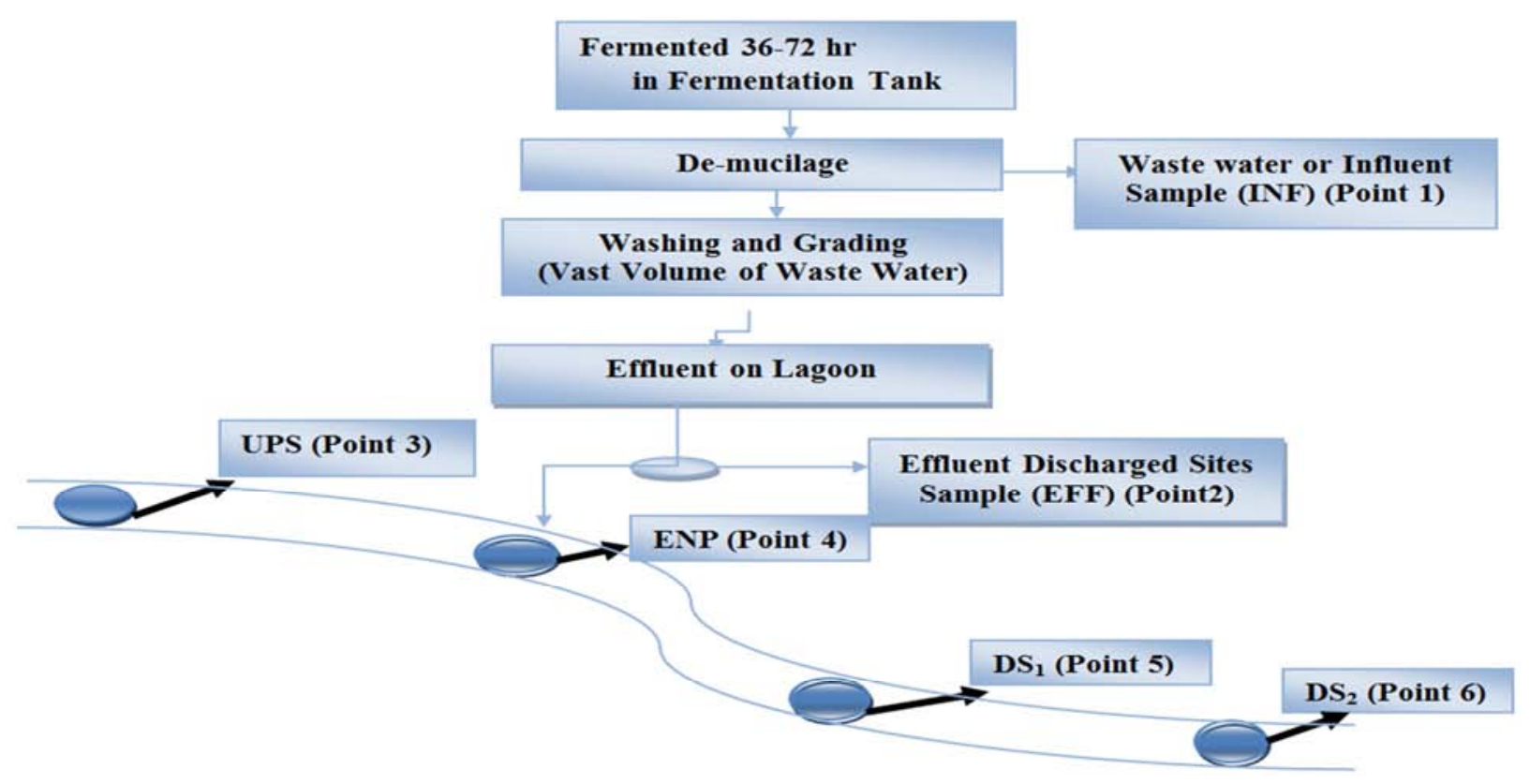

Figure 2. Map indicating general flow diagram of coffee refinery and effluent sampling sites.

\subsubsection{Sampling Procedure of Physicochemical Parameters Data}

Two liters of water samples were collected in sterilized plastic BOD bottles and glass bottles from each site, kept in a container with ice, and transported to the laboratory to maintain accuracy or minimize contamination of physicochemical changes that can occur between time of collection and analysis as indicated in America Public Health Association (APHA) standard method [13]. These water samples were collected by inserting the plastic and glass bottles to the opposite direction of the river flow and capped tightly immediately after filling to the tip of the mouth of this bottle by using depth-integrated sampling technique. Water quality variables such as $\mathrm{pH}$, water temperature, dissolved oxygen (DO), turbidity, and electrical conductivity (EC) were 
measured at in-situ using a HI 98290 multi parameter meter with a HI $7639829 / 10$ probe (HANNA Instruments, Woonsocket, RI, USA). The probe was gently stirred in a 5-L bucket filled with river water for at least 40 seconds. The other water quality, chemical and biological samples were determined according to the APHA standard method [13] for the examination of water and wastewater as putted in the table below.

Table 1. Physico-chemical parameters selected for the study site and techniques used for sample of analysis 。

\begin{tabular}{|c|c|c|c|c|}
\hline S.NO & Physico-chemical parameters & Abbreviations & Methods of sample analysis & Units \\
\hline 1 & Water temperature & WT & Probes multi parameter methods & ${ }^{\circ} \mathrm{C}$ \\
\hline 2 & Turbidity & TURB & Turbidity meter & NTU \\
\hline 3 & Electrical conductivity & $\mathrm{EC}$ & Probes multi parameter methods (EC meter) & $\mu \mathrm{S} / \mathrm{cm}$ \\
\hline 4 & $\mathrm{pH}$ & $\mathrm{pH}$ & Probes multi parameter methods ( $\mathrm{pH}$ meter) & - \\
\hline 5 & Total Dissolved Solids & TDS & Gravimetric Method, dried at $180^{\circ} \mathrm{C}$ & $\mathrm{mg} / \mathrm{L}$ \\
\hline 6 & Total Suspended solid & TSS & Gravimetric Method, dried at $103-105^{\circ} \mathrm{C}$ & $\mathrm{mg} / \mathrm{L}$ \\
\hline 7 & Total Solid (TS) & TS & Gravimetric Method, dried at $103-105^{\circ} \mathrm{C}$ & $\mathrm{mg} / \mathrm{L}$ \\
\hline 9 & Biological Oxygen Demand & $\mathrm{BOD}_{5}$ & The Azide Modification of the Winkler Method & $\mathrm{mg} / \mathrm{L}$ \\
\hline 10 & Chemical oxygen demand & COD & Kit (Hachlange cuvette test, LCk 614 \&114) & $\mathrm{mg} / \mathrm{L}$ \\
\hline 11 & Nitrate-Nitrogen & $\mathrm{NO}_{3}-\mathrm{N}$ & Phenoldisulfonic Acid Method & $\mathrm{mg} / \mathrm{L}$ \\
\hline 12 & Ammonia-Nitrogen & $\mathrm{NH}_{3}-\mathrm{N}$ & Direct Nesslerization Method & $\mathrm{mg} / \mathrm{L}$ \\
\hline 13 & Total nitrogen & $\mathrm{TN}$ & Kit (Hachlange cuvette test, LCK 138 \& 338) & $\mathrm{mg} / \mathrm{L}$ \\
\hline 14 & Orthophosphate & $\mathrm{O}-\mathrm{PO}_{4}{ }^{3-}$ & Stannous Chloride Method & $\mathrm{mg} / \mathrm{L}$ \\
\hline
\end{tabular}

Source: APHA standard method [13].

\subsubsection{Sampling Method of Benthos for Environmental Flows}

Benthos community was sampled, identified, and quantified according to the method described, which is an internationally accepted kick-sampling procedure for benthos sampling. The sampling effort was equally divided into three (these three samples were taken cross sectionally: two corners and one center) over the different habitats per sampling site. Benthos sample was conducted three times from each riffle and runs sample sites. The sampling was realized via a 10-minute kick-sampling technique with a rectangular kicking net $(20 \times 30 \mathrm{~cm})$ with a mesh size of $300 \mu \mathrm{m}$ over a distance of $10 \mathrm{~m}$ Niels De Troyeret al. [14]. The organisms were sorted in the field and stored into labeled vials with an $80 \%$ ethanol solution. Afterwards, they were transferred to the lab for identification to family level using a stereomicroscope (10X and $20 \mathrm{X}$ magnifications) and the identification keys of [15-17].

\subsubsection{Data Quality Management}

Certified standard methods were used for all procedure of the set of experiments. All reagents were of analytical grade and their expiry dates were checked. For each test, replicate sample analysis was made to maintain accuracy. Blank and control experiments were run. The results of all tests were honestly and cautiously recorded on a prepared data registration format APHA standard method [13].

\subsubsection{Statistical Analysis}

SAS version 9.2, Minitab Version 16.0 software and MS Excel, were used to analyses data. ANOVA were used to determine the significant difference of concentrations for various physic-chemical parameters and benthos assemblages. Benthos assemblages as biological indicators of Eflows were test by using benthos assemblage's multi metric indices. Mean separation of difference in concentration levels obtained for a given parameter along Eflows \& sampling sites were considered as significant if calculated P-values were $<0.05$. To evaluate its capacity of coffee wastewater (organic load) and nutrients treatment performance of the conventional lagoon pond (traditionally waste stabilization ponds) were calculated using following formula of [2].

$$
\text { Removalefficiency }(\%)=\frac{(\mathrm{C} \text { in } \mathrm{f}-\mathrm{C} \text { eff }) \text { X } 100}{(\mathrm{C} \text { inf })}
$$

Where Cinf $=$ initial parameter concentration and Ceff $=$ final parameter concentration. Spearman rank correlations analysis was used to indicate the relationships between Eflows and benthos assemblage's variables to evaluate with among sampling site differences.

\subsubsection{Ethical clearance}

Ethical clearance was obtained from the Ethical Committee of the Jimma University, College of Agriculture \& Veterinary Medicine (JUCAVM). The laboratory analysis was followed scientific procedures and the results were recorded honestly in data collection formats. In addition, authors of books and journals that are used were cited properly. Scholars, individuals, and organizations contributed for the successful completion of this study were also acknowledged.

\section{Results}

\subsection{Significant Level of Physical Parameters Characteristics Between Eflows and Sampling Sites}

The average mean values of water temperature were ranged between $12.11 \pm 0.78-43.09 \pm 0.78^{\circ} \mathrm{C}$ at Kebena UPS and Awetu EFF respectively. This result showed that highly significant difference in all sampling sites but very high $43.96^{\circ} \mathrm{C}$ in the Awetu EFF at $(\mathrm{p}<0.05 \& 0.01)$. There were highly significant difference in the concentration of EC among the four river water and sites at $(p<0.05$ and 0.01$)$. The 
average mean values of EC ranged from 167.65 \pm $15.38-1187.26 \pm 15.38 \mu \mathrm{S} / \mathrm{cm}$ among all sites. $\mathrm{DS}_{1}$ to $\mathrm{DS}_{2}$ exhibited not significant variation of EC \& TDS in contrast to other sites. The EC was alarmingly increased with the increased in TDS \& water temperature (Table 2). The observed turbidity mean values ranged from $3.3 \pm$ 11.05-1363.67 $\pm 11.05 \mathrm{NTU}$ at Bonke UPS \& Kebena INF respectively. The maximum average mean value obtained from the polluted sites (1397NTU) was higher than 2.86NTU recorded at UPS. The turbidity mean concentration at $\mathrm{DS}_{1}$ to $\mathrm{DS}_{2}$ was $114.10 \pm 11.05-980.58 \pm 11.05 \mathrm{NTU}$. Consequently, various analytical mean values of TSS \& TDS were fluctuated between $756.35 \pm 15.31-1063.35 \pm 15.31 \mathrm{mg} / \mathrm{L}$ to $394.14 \pm$
15.31-342.09 $\pm 15.31 \mathrm{mg} / \mathrm{L}$ and $1095.64 \pm 53.71-1197.37 \pm$ $53.71 \mathrm{mg} / \mathrm{L}$ to $435.26 \pm 53.71-481.92 \pm 53.71 \mathrm{mg} / \mathrm{L}$ amongst the polluted sites of Kebena \& Ketalenca $\mathrm{DS}_{1}$ to $\mathrm{DS}_{2}$ respectively. These mean values of TSS \& TDS obtained from the polluted sites were higher than $16.79 \pm 15.31-10.02 \pm$ $15.31 \mathrm{mg} / \mathrm{L}$ to $302.96 \pm 53.71-235.04 \pm 53.71 \mathrm{mg} / \mathrm{L}$ recorded at Kebena \& Ketalenca UPS respectively. There were highly significant differences $(\mathrm{p}<0.05$ and 0.01$)$ in the values of TSS among the different sampling sites across the river water bodies located nearby. These results showed that significantly increased values from $\mathrm{DS}_{1}$ to $\mathrm{DS}_{2}$ sites of the river water in TSS, but not significant differences from $\mathrm{DS}_{1}$ to $\mathrm{DS}_{2}$ in TDS (table 2).

Table 2. Interaction effects of effluent discharges by conventional wet washed coffee refineries (CWCR) based on physical characteristics between Eflows and sampling sites.

\begin{tabular}{|c|c|c|c|c|c|c|c|}
\hline \multicolumn{8}{|c|}{ Mean separation of Physical parameters } \\
\hline Rivers & Site & TSS & TDS & TS & EC & TURB & WT \\
\hline \multirow[t]{6}{*}{ Kebena } & EFF & $1800.35^{\mathrm{A}}$ & $2239.30^{\mathrm{B}}$ & $4039.64^{\mathrm{BA}}$ & $1045.80^{\mathrm{B}}$ & $1335.23^{\mathrm{A}}$ & $28.12 \mathrm{EF}$ \\
\hline & INF & $1527.23^{\mathrm{B}}$ & $2681.23^{\mathrm{A}}$ & $4208.46^{\mathrm{A}}$ & $1160.68^{\mathrm{A}}$ & $1363.67^{\mathrm{A}}$ & $37.267^{\mathrm{B}}$ \\
\hline & ENP & $1460.03^{\mathrm{CB}}$ & $2052.26^{\mathrm{B}}$ & $3512.29^{\mathrm{ED}}$ & $858.65^{\mathrm{C}}$ & $1190.48^{\mathrm{B}}$ & $24.27^{\mathrm{FIHG}}$ \\
\hline & $\mathrm{DS}_{2}$ & $1063.35^{\mathrm{D}}$ & $1197.37^{\mathrm{E}}$ & $2260.72^{\mathrm{HG}}$ & $661.09^{\mathrm{D}}$ & $980.58^{\mathrm{C}}$ & $19.60^{\mathrm{JK}}$ \\
\hline & $\mathrm{DS}_{1}$ & $756.35^{\mathrm{E}}$ & $1095.64^{\mathrm{E}}$ & $1851.98^{\mathrm{JI}}$ & $616.73^{\mathrm{D}}$ & $972.10^{\mathrm{C}}$ & $18.67^{\mathrm{K}}$ \\
\hline & UPS & $16.79^{\mathrm{I}}$ & $302.96^{\mathrm{GH}}$ & $319.75^{\mathrm{M}}$ & $188.65^{\mathrm{H}}$ & $3.99^{\mathrm{H}}$ & $12.11^{\mathrm{L}}$ \\
\hline \multirow[t]{6}{*}{ Awetu } & $\mathrm{EFF}$ & $1778.87^{\mathrm{A}}$ & $1508.64^{\mathrm{DC}}$ & $3287.51^{\mathrm{EF}}$ & $1035.56^{\mathrm{B}}$ & $1195.25^{\mathrm{B}}$ & $43.09^{\mathrm{A}}$ \\
\hline & INF & $1126.52^{\mathrm{D}}$ & $2773.59^{\mathrm{A}}$ & $3900.1^{\mathrm{BAC}}$ & $1187.26^{\mathrm{A}}$ & $1188.10^{\mathrm{B}}$ & $36.75^{\mathrm{B}}$ \\
\hline & ENP & $586.98^{\mathrm{F}}$ & $1537.99^{C}$ & $2124.97^{\mathrm{HI}}$ & $844.00^{\mathrm{C}}$ & $675.94^{\mathrm{D}}$ & $34.97^{\mathrm{CB}}$ \\
\hline & $\mathrm{DS}_{2}$ & $431.65^{\mathrm{G}}$ & $762.07^{\mathrm{F}}$ & $1193.72^{\mathrm{K}}$ & $505.65^{\mathrm{E}}$ & $514.38^{\mathrm{E}}$ & $25.40^{\mathrm{FHG}}$ \\
\hline & $\mathrm{DS}_{1}$ & $434.23^{\mathrm{G}}$ & $753.82^{\mathrm{F}}$ & $1188.05^{\mathrm{K}}$ & $513.28^{\mathrm{E}}$ & $514.56^{\mathrm{E}}$ & $29.747^{\mathrm{ED}}$ \\
\hline & UPS & $33.24^{\mathrm{I}}$ & $335.24^{\mathrm{GH}}$ & $368.48^{\mathrm{M}}$ & $197.94^{\mathrm{H}}$ & $6.99^{\mathrm{H}}$ & $20.08^{\mathrm{JIK}}$ \\
\hline \multirow[t]{6}{*}{ Bonke } & $\mathrm{EFF}$ & $757.29^{\mathrm{E}}$ & $2298.43^{\mathrm{B}}$ & $3055.72^{\mathrm{F}}$ & $890.99^{\mathrm{C}}$ & $1316.66^{\mathrm{A}}$ & $37.82^{\mathrm{B}}$ \\
\hline & INF & $1382.24^{\mathrm{C}}$ & $2202.67^{\mathrm{B}}$ & $3584.9^{\mathrm{EDC}}$ & $1151.17^{\mathrm{A}}$ & $1202.01^{\mathrm{B}}$ & $37.27^{\mathrm{B}}$ \\
\hline & ENP & $578.45^{\mathrm{F}}$ & $1227.24^{\mathrm{DE}}$ & $1805.68^{\mathrm{J}}$ & $582.78^{\mathrm{ED}}$ & $520.62^{\mathrm{E}}$ & $36.86^{\mathrm{B}}$ \\
\hline & $\mathrm{DS}_{2}$ & $543.76^{\mathrm{F}}$ & $577.02^{\mathrm{F}}$ & $1120.78^{\mathrm{LK}}$ & $395.69^{F}$ & $128.70^{\mathrm{G}}$ & $23.64^{\mathrm{JIHG}}$ \\
\hline & $\mathrm{DS}_{1}$ & $584.03^{\mathrm{F}}$ & $569.84^{\mathrm{GF}}$ & $1153.87^{\mathrm{K}}$ & $393.62^{\mathrm{F}}$ & $128.39^{\mathrm{G}}$ & $35.77^{\mathrm{B}}$ \\
\hline & UPS & $28.07^{\mathrm{I}}$ & $230.00^{\mathrm{H}}$ & $258.07^{\mathrm{M}}$ & $167.65^{\mathrm{H}}$ & $3.30^{\mathrm{H}}$ & $27.32^{\text {FEG }}$ \\
\hline \multirow[t]{15}{*}{ Ketalenca } & $\mathrm{EFF}$ & $1381.05^{\mathrm{C}}$ & $1177.33^{\mathrm{E}}$ & $2558.38^{\mathrm{G}}$ & $1015.70^{\mathrm{B}}$ & $1352.37^{\mathrm{A}}$ & $31.29^{\mathrm{CED}}$ \\
\hline & INF & $1051.68^{\mathrm{D}}$ & $2746.18^{\mathrm{A}}$ & $3797.86^{\mathrm{BDC}}$ & $1179.37^{\mathrm{A}}$ & $1237.58^{\mathrm{B}}$ & $33.95^{\mathrm{CBD}}$ \\
\hline & ENP & $419.74^{\mathrm{HG}}$ & $753.73^{\mathrm{F}}$ & $1173.47^{\mathrm{K}}$ & $318.35^{\mathrm{GF}}$ & $334.88^{\mathrm{F}}$ & $30.10^{\mathrm{ED}}$ \\
\hline & $\mathrm{DS}_{2}$ & $342.09^{\mathrm{H}}$ & $481.92^{\mathrm{GFH}}$ & $824.02^{\mathrm{L}}$ & $240.14^{\mathrm{GH}}$ & $122.30^{\mathrm{G}}$ & $21.36^{\mathrm{JHHK}}$ \\
\hline & $\mathrm{DS}_{1}$ & $394.14^{\mathrm{HG}}$ & $435.26^{\mathrm{GH}}$ & $829.39^{\mathrm{L}}$ & $226.71^{\mathrm{H}}$ & $114.10^{\mathrm{G}}$ & $19.60^{\mathrm{JK}}$ \\
\hline & UPS & $10.02^{\mathrm{I}}$ & $235.04^{\mathrm{H}}$ & $245.06^{\mathrm{M}}$ & $169.10^{\mathrm{H}}$ & $5.12^{\mathrm{H}}$ & $14.28^{\mathrm{L}}$ \\
\hline & Mean & 770.34 & 1257 & 2028 & 647.77 & 683.64 & 28.31 \\
\hline & Max & 1812 & 2816 & 4302 & 1227.16 & 1397 & 43.96 \\
\hline & Min & 9.70 & 222.27 & 236.84 & 165.43 & 2.86 & 11.70 \\
\hline & WHO & 500 & 1000 & 500 & 1000 & 10 & - \\
\hline & CV (\%) & 3.44 & 7.39 & 4.98 & 4.11 & 2.80 & 4.78 \\
\hline & MSD & 83.45 & 292.79 & 318.08 & 83.85 & 60.24 & 4.26 \\
\hline & $\operatorname{SEM}( \pm)$ & 15.31 & 53.71 & 58.35 & 15.38 & 11.05 & 0.78 \\
\hline & River & $<.0001$ & $<.0001$ & $<.0001$ & $<.0001$ & $<.0001$ & $<.0001$ \\
\hline & River*Site & $<.0001$ & $<.0001$ & $<.0001$ & $<.0001$ & $<.0001$ & $<.0001$ \\
\hline
\end{tabular}

Note: CV (Coefficient of Variation in percent), MSD (minimum significance difference at 5\% and 1\%), SEM (Standard error mean). Mean with different letters in the same column were significantly different (withTukey's test at $5 \%$ and $1 \%$ level of probability) as established by MSD test. Except EC ( $\mu$ S/cm), TURB (NTU), and WT $\left({ }^{\circ} \mathrm{C}\right)$ the others parameters were expressed in $\mathrm{mg} / \mathrm{L}$. These six river sites were averages among each site. Awetu and Kebena River water from private and the other two were from the government refineries. Significant interactions and main effects were explored by Tukey's test, using the GLM procedure at $\mathrm{P}<0.05$ and 0.01 as established by MSD test.

\subsection{Significant Level of Chemical Parameters Characteristics Between Eflows and Sampling Sites}

The average mean values of $\mathrm{pH}$ at all six sites of river water were acidic and ranged between $3.12 \pm 0.10-7.67 \pm 0.10$ at
Kebena EFF and Awetu UPS respectively. The lowest values of obtained from the EFF (2.9) which was very lower than 7.93 recorded at UPS. Acidity was found to be potent at ENP than $\mathrm{DS}_{1}$ which in turn was stronger than $\mathrm{DS}_{2}$ (table 3). The $\mathrm{pH}$ has shown significant differences among $\mathrm{DS}_{1}$ and $\mathrm{DS}_{2}$ 
river water at $(\mathrm{p}<0.05$ and 0.01$)$. The average mean values of DO were fluctuated between $0.00 \pm 0.10$ to $8.04 \pm 0.10 \mathrm{mg} / \mathrm{L}$ in river water samples collected among the four-river water with river water and sites. The Kebena EFF and INF showed the lowest value of DO as $0.00 \pm 0.10 \mathrm{mg} / \mathrm{L}$. Level of DO in the river water was almost normal in the UPS (Table 3). There were highly significant inconsistencies of interaction effect of BOD and COD among all river waters at $(p<0.05$ and 0.01$)$. The maximum average mean values BOD and COD were recorded $(2972.67 \pm 30.27$ to $2576.05 \pm 30.37 \mathrm{mg} / \mathrm{L})$ at Kebena EFF and INF with minimum values were recorded $(2.36 \pm 30.27$ to $3.99 \pm 30.37 \mathrm{mg} / \mathrm{L})$ at Ketalenca and Bonke UPS. There was an increment of BOD and COD from (1773 \pm $30.27-1719.83 \pm 30.37 \mathrm{mg} / \mathrm{L})$ to $(1797.89 \pm 30.27$ to 1836.40 $\pm 30.37 \mathrm{mg} / \mathrm{L})$ at Kebena $\mathrm{DS}_{1}$ and $\mathrm{DS}_{2}$ then it decreased slowly towards the rest of the Ketalenca and Bonke of $\mathrm{DS}_{1}$ and
$\mathrm{DS}_{2}$ respectively. TN concentration analysis revealed that highly significant difference in interaction effect among the four rivers but not at Kebena river of ENP, $\mathrm{DS}_{1}, \mathrm{DS}_{2}$ and Bonke ENP as well as EFF and PUS of all river water at $(\mathrm{p} \leq$ 0.05 and 0.01 ). This is due to highly mobility or fixation of TN concentration among each river water sites. The concentrations of $\mathrm{NO}_{3}-\mathrm{N}$ and $\mathrm{NH}_{3}-\mathrm{N}$ in the river water were found to be statistically highly significant and the average mean values were ranging from $2.43 \pm 0.03$ to $4.99 \pm$ $0.07 \mathrm{mg} / \mathrm{L}$ on the other hand it were higher concentration at all INF and showed that alarmingly increment from $\mathrm{DS}_{1}$ to $\mathrm{DS}_{2}$ due to high CWCR activities that ultimately discharge almost untreated effluent to the river (Table 3 ). The average mean values of $\mathrm{O}-\mathrm{PO}_{4}{ }^{3-}$ were showed that significant difference with all river water but not at $\mathrm{DS}_{1}$ and $\mathrm{DS}_{2}$ difference among all river water (table 3 ).

Table 3. Interaction effects of effluent discharges by conventional wet washed coffee refineries (CWCR) based on chemical characteristics between Eflows quality and sampling sites

\begin{tabular}{|c|c|c|c|c|c|c|c|c|c|}
\hline \multicolumn{10}{|c|}{ Mean separation of Chemical parameters } \\
\hline River & Site & $\mathbf{p H}$ & BOD & COD & DO & $\mathbf{T N}$ & $\mathrm{NO}_{3}-\mathrm{N}$ & $\mathrm{NH}_{3}-\mathrm{N}$ & Ort-P \\
\hline \multirow[t]{6}{*}{ Kebena } & EFF & $3.12^{\mathrm{I}}$ & $2972.67^{\mathrm{A}}$ & $2735.50^{\mathrm{A}}$ & $0.00^{\mathrm{H}}$ & $98.40^{\mathrm{A}}$ & $3.36^{\mathrm{C}}$ & $7.04^{\mathrm{C}}$ & $13.18^{\mathrm{E}}$ \\
\hline & INF & $3.33^{\mathrm{HI}}$ & $2689.67^{\mathrm{B}}$ & $2576.05^{\mathrm{A}}$ & $0.01^{\mathrm{H}}$ & $92.60^{\mathrm{BA}}$ & $3.86^{\mathrm{A}}$ & $8.11^{\mathrm{A}}$ & $22.90^{\mathrm{A}}$ \\
\hline & ENP & $3.36^{\mathrm{HI}}$ & $2478.88^{\mathrm{C}}$ & $1940.57^{\mathrm{B}}$ & $0.02^{\mathrm{H}}$ & $78.61^{\mathrm{DE}}$ & $3.08^{\mathrm{D}}$ & $6.92^{\mathrm{DCE}}$ & $10.87^{\mathrm{F}}$ \\
\hline & $\mathrm{DS}_{2}$ & $4.06^{\mathrm{DGEF}}$ & $1797.89^{\mathrm{E}}$ & $1836.40^{\mathrm{CB}}$ & $0.05^{\mathrm{H}}$ & $76.22^{\mathrm{DE}}$ & $2.81^{\mathrm{E}}$ & $6.83^{\mathrm{DCE}}$ & $10.83^{\mathrm{F}}$ \\
\hline & $\mathrm{DS}_{1}$ & $4.28^{\mathrm{D}}$ & $1773.00^{\mathrm{FE}}$ & $1719.83^{\mathrm{C}}$ & $0.07^{\mathrm{H}}$ & $76.66^{\mathrm{DE}}$ & $2.74^{\mathrm{FE}}$ & $6.65^{\mathrm{DE}}$ & $10.34^{\mathrm{F}}$ \\
\hline & UPS & $7.43^{\mathrm{A}}$ & $6.70^{\mathrm{I}}$ & $4.57^{\mathrm{G}}$ & $8.04^{\mathrm{A}}$ & $0.31^{\mathrm{K}}$ & $0.03^{\mathrm{J}}$ & $0.07^{\mathrm{K}}$ & $0.34^{\mathrm{I}}$ \\
\hline \multirow[t]{6}{*}{ Awetu } & $\mathrm{EFF}$ & $3.59^{\mathrm{HG} \mathrm{IF}}$ & $2254.95^{\mathrm{D}}$ & $1850.27^{\mathrm{CB}}$ & $0.11^{\mathrm{H}}$ & $88.72^{\mathrm{BC}}$ & $3.09^{\mathrm{D}}$ & $7.00^{\mathrm{DC}}$ & $11.47^{\mathrm{F}}$ \\
\hline & INF & $3.31^{\mathrm{HI}}$ & $2205.32^{\mathrm{D}}$ & $1982.94^{\mathrm{B}}$ & $0.12^{\mathrm{H}}$ & $94.57^{\mathrm{BA}}$ & $3.60^{\mathrm{B}}$ & $7.49^{\mathrm{B}}$ & $20.37^{\mathrm{B}}$ \\
\hline & ENP & $3.71^{\mathrm{HG} \mathrm{EF}}$ & $1868.24^{\mathrm{E}}$ & $1525.88^{\mathrm{D}}$ & $1.49^{\mathrm{E}}$ & $82.56^{\mathrm{DC}}$ & $2.67^{\mathrm{FE}}$ & $6.93^{\mathrm{DCE}}$ & $11.00^{\mathrm{F}}$ \\
\hline & $\mathrm{DS}_{2}$ & $4.12^{\mathrm{DEF}}$ & $1010.05^{\mathrm{HG}}$ & $1020.21^{\mathrm{FE}}$ & $3.16^{\mathrm{C}}$ & $35.14^{\mathrm{H}}$ & $2.64^{\mathrm{F}}$ & $6.63^{\mathrm{FE}}$ & $10.82^{\mathrm{F}}$ \\
\hline & $\mathrm{DS}_{1}$ & $4.20^{\mathrm{DE}}$ & $989.30^{\mathrm{HG}}$ & $1035.08^{\mathrm{FE}}$ & $3.33^{\mathrm{C}}$ & $21.10^{\mathrm{J}}$ & $2.64^{\mathrm{F}}$ & $6.63^{\mathrm{GF}}$ & $10.40^{\mathrm{F}}$ \\
\hline & UPS & $7.67^{\mathrm{A}}$ & $9.75^{\mathrm{I}}$ & $8.96^{\mathrm{G}}$ & $6.64^{\mathrm{B}}$ & $5.44^{\mathrm{K}}$ & $0.66 \mathrm{I}$ & $0.06^{\mathrm{K}}$ & $0.91^{\mathrm{I}}$ \\
\hline \multirow[t]{6}{*}{ Bonke } & $\mathrm{EFF}$ & $4.15^{\mathrm{DEF}}$ & $1849.67^{\mathrm{E}}$ & $1451.67^{\mathrm{D}}$ & $1.23^{\mathrm{FE}}$ & $96.02^{\mathrm{A}}$ & $2.98^{\mathrm{D}}$ & $5.40^{\mathrm{H}}$ & $15.40^{\mathrm{D}}$ \\
\hline & INF & $3.55^{\mathrm{HGI}}$ & $2201.63^{D}$ & $1835.09^{\mathrm{CB}}$ & $0.14^{\mathrm{H}}$ & $72.47^{\mathrm{FE}}$ & $3.97^{\mathrm{A}}$ & $6.01^{\mathrm{G}}$ & $17.56^{\mathrm{C}}$ \\
\hline & ENP & $4.96^{\mathrm{C}}$ & $1129.35^{\mathrm{G}}$ & $1163.20^{\mathrm{E}}$ & $2.15^{\mathrm{D}}$ & $77.62^{\mathrm{DE}}$ & $2.78^{\mathrm{FE}}$ & $6.14^{\mathrm{G}}$ & $13.79^{\mathrm{E}}$ \\
\hline & $\mathrm{DS}_{2}$ & $5.69^{\mathrm{B}}$ & $1030.60^{\mathrm{HG}}$ & $928.69^{\mathrm{F}}$ & $3.40^{\mathrm{C}}$ & $13.06^{\mathrm{I}}$ & $1.35^{\mathrm{H}}$ & $3.83^{\mathrm{J}}$ & $8.28^{\mathrm{G}}$ \\
\hline & $\mathrm{DS}_{1}$ & $5.57^{\mathrm{B}}$ & $992.55^{\mathrm{HG}}$ & $961.88^{\mathrm{F}}$ & $3.55^{\mathrm{C}}$ & $41.52^{\mathrm{H}}$ & $1.95^{\mathrm{G}}$ & $3.81^{\mathrm{J}}$ & $8.19^{\mathrm{G}}$ \\
\hline & UPS & $7.52^{\mathrm{A}}$ & $4.34^{\mathrm{I}}$ & $3.99^{\mathrm{G}}$ & $6.14^{\mathrm{B}}$ & $4.47^{\mathrm{K}}$ & $0.66^{\mathrm{I}}$ & $0.07^{\mathrm{K}}$ & $0.13^{\mathrm{I}}$ \\
\hline \multirow[t]{15}{*}{ Ketalenca } & EFF & $3.48^{\mathrm{HI}}$ & $1618.17^{\mathrm{F}}$ & $1488.03^{\mathrm{D}}$ & $0.73^{\mathrm{FG}}$ & $95.29^{\mathrm{A}}$ & $3.09^{\mathrm{D}}$ & $5.12^{\mathrm{H}}$ & $8.25^{\mathrm{G}}$ \\
\hline & INF & $4.55^{\mathrm{DC}}$ & $1717.18^{\mathrm{FE}}$ & $1551.15^{\mathrm{D}}$ & $0.25^{\mathrm{HG}}$ & $66.36^{\mathrm{F}}$ & $3.60^{\mathrm{B}}$ & $6.29^{\mathrm{FE}}$ & $10.60^{\mathrm{F}}$ \\
\hline & ENP & $4.60^{\mathrm{DC}}$ & $1109.83^{\mathrm{G}}$ & $1014.92^{\mathrm{FE}}$ & $2.19^{\mathrm{D}}$ & $50.09^{\mathrm{G}}$ & $2.64^{\mathrm{F}}$ & $4.62^{I}$ & $8.84^{\mathrm{G}}$ \\
\hline & $\mathrm{DS}_{2}$ & $5.90^{\mathrm{B}}$ & $902.88^{\mathrm{H}}$ & $874.23^{\mathrm{F}}$ & $3.64^{\mathrm{C}}$ & $19.88^{\mathrm{I}}$ & $1.51^{\mathrm{H}}$ & $3.83^{\mathrm{J}}$ & $4.86^{\mathrm{H}}$ \\
\hline & $\mathrm{DS}_{1}$ & $5.66^{\mathrm{B}}$ & $1009.38^{\mathrm{HG}}$ & $912.93^{\mathrm{F}}$ & $3.27^{\mathrm{C}}$ & $35.31^{\mathrm{H}}$ & $1.96^{\mathrm{G}}$ & $4.26^{\mathrm{I}}$ & $5.84^{\mathrm{H}}$ \\
\hline & UPS & $7.52^{\mathrm{A}}$ & $2.36^{\mathrm{I}}$ & $9.74^{\mathrm{G}}$ & $8.01^{\mathrm{A}}$ & $5.87^{\mathrm{K}}$ & $0.66^{\mathrm{I}}$ & $0.05^{\mathrm{K}}$ & $0.34^{\mathrm{I}}$ \\
\hline & Mean & 4.80 & 1401 & 1268 & 2.41 & 55.35 & 2.43 & 4.99 & 9.81 \\
\hline & Max & 7.93 & 2993 & 2867 & 8.31 & 99.23 & 3.99 & 8.37 & 23.31 \\
\hline & Min & 2.90 & 2.03 & 3.19 & 0.00 & 0.30 & 0.03 & 0.05 & 0.13 \\
\hline & WHO & $65-8.5$ & 10 & 40 & 6 & - & $10-45$ & $0.2-5$ & 5 \\
\hline & CV (\%) & 6.03 & 6.74 & 8.16 & 5.80 & 3.71 & 2.17 & 2.30 & 3.97 \\
\hline & MSD & 0.56 & 165.01 & 165.57 & 0.52 & 6.48 & 0.17 & 0.36 & 1.23 \\
\hline & $\operatorname{SEM}( \pm)$ & 0.10 & 30.27 & 30.37 & 0.10 & 1.19 & 0.03 & 0.07 & 0.23 \\
\hline & River & $<.0001$ & $<.0001$ & $<.0001$ & $<.0001$ & $<.0001$ & $<.0001$ & $<.0001$ & $<.0001$ \\
\hline & River*Site & $<.0001$ & $<.0001$ & $<.0001$ & $<.0001$ & $<.0001$ & $<.0001$ & $<.0001$ & $<.0001$ \\
\hline
\end{tabular}

Note: CV (Coefficient of Variation in percent), MSD (minimum significance difference at 5\% and 1\%), SEM (Standard error mean). Mean with different letters in the same column were significantly different (with Tukey's test at 5\% and 1\% level of probability) as established by MSD test. Except pH, the others parameters were expressed in $\mathrm{mg} / \mathrm{L}$. These six river sites were averages among each site. Awetu and Kebena River water from private and the other two were from the government refineries. Significant interactions and main effects were explored by Tukey's test, using the GLM procedure at P $<0.05$ and 0.01 as established by MSD test. 


\subsection{Capacity of Coffee Wastewater Treatment Performance of the Conventional Lagoon Pond}

Capacity of conventional wet coffee wastewater treatment performance of the conventional lagoon pond (traditionally waste stabilization ponds) before disposed into environmental flows based on the physicochemical parameters during the sampling period were presented in table 4 below. The conventional lagoon pond (traditionally waste stabilization ponds) removal efficiency of organic load ranged between $20.89 \%$ to $10.52 \%$ and solids was $57.13 \%$ to $-17.88 \%$, and for nutrients, it was about 43.69 to $32.50 \%$. Negative percentage recoveries showed that low adsorption level by efficiency of conventional lagoon pond (table 4).

Table 4. Capacity of conventional wet coffee wastewater treatment performance of the conventional lagoon pond before disposed into environmental flows

\begin{tabular}{|c|c|c|c|c|c|c|c|c|c|c|}
\hline River & $\mathrm{pH}$ & BOD & COD & TN & Ort-P & TSS & TDS & TS & EC & TURB \\
\hline Kebena & 6.31 & -10.52 & -6.19 & -6.26 & 42.45 & -17.88 & 16.48 & 4.01 & 9.90 & 2.09 \\
\hline Awetu & -8.46 & -2.25 & 6.69 & 6.19 & 43.69 & -6.52 & 12.65 & 6.13 & 1.52 & -0.07 \\
\hline Bonke & -16.90 & 15.99 & 20.89 & -32.50 & 12.30 & 45.21 & -4.35 & 14.76 & 22.60 & -9.54 \\
\hline
\end{tabular}

\subsection{Spatial Distribution of Benthos Assemblages as Best Indicators of Bio-assessment of Environmental Flows}

Species composition and distribution of benthos in four river water bodies nearby CWCR showed differences between them which based on the presence or absence of some specie. 1293 individuals belonging to 30 families in 8 taxonomic orders, were identified in the four major river water bodies nearby conventional wet coffee refineries during the survey. A total number of individuals found in the $\mathrm{DS}_{2}$ were 387 as compared to 906 individuals collected from the UPS. The taxa of Ephemeroptera, Hemiptera, Trichoptera, Plecoptera, and Coleoptera were present in greater number in the UPS as compared to $\mathrm{DS}_{2}$. On the other hand, pollution tolerant species of families Chironomidae, Simuliidae, and Leeches were present in greater number in the $\mathrm{DS}_{2}$ sections throughout the experimental period (table 5).

Table 5. Diversity indices of benthos in river water bodies nearby conventional wet coffee refineries.

\begin{tabular}{|c|c|c|c|c|c|c|c|c|c|c|}
\hline Rivers & $\mathbf{F}$ & & $\mathbf{S}$ & & D & & H' & & $\mathbf{E}$ & \\
\hline & UPS & $\mathrm{DS}_{2}$ & UPS & $\mathrm{DS}_{2}$ & UPS & $\mathrm{DS}_{2}$ & UPS & $\mathrm{DS}_{2}$ & UPS & $\mathrm{DS}_{2}$ \\
\hline Awetu & 9 & 11 & 266 & 157 & 0.88 & 0.85 & 2.15 & 2.09 & 0.98 & 0.89 \\
\hline Bonke & 9 & 6 & 169 & 54 & 0.88 & 0.63 & 2.14 & 1.32 & 0.97 & 0.74 \\
\hline Kebena & 13 & 3 & 205 & 49 & 0.92 & 0.50 & 2.54 & 0.87 & 0.99 & 0.79 \\
\hline Average & & & & & 0.90 & 0.64 & 2.36 & 1.40 & 0.98 & 0.76 \\
\hline
\end{tabular}

Analysis of the results of diversity indices of benthos in river water bodies nearby CWCR as biological indicators illustrated a highly significant difference between four rivers and all sites at $(\mathrm{p}<0.05$ and 0.01$)$. The analysis of the average species diversity indices of benthos as biological indicators
(Shannon, equitability and Simpson) were much reduced in the $\mathrm{DS}_{2}$ as against UPS very high were recorded throughout the experimental period (Tables 5 and 6). H' and D values decreased consistently from the UPS to the $\mathrm{DS}_{2}$.

Table 6. Results of ANOVA for diversity indices of benthos in river water bodies nearby conventional wet coffee refineries (CWCR).

\begin{tabular}{|c|c|c|c|c|c|}
\hline \multicolumn{6}{|c|}{ Mean separation of diversity indices of benthos } \\
\hline Site & $\mathbf{F}$ & $\mathbf{S}$ & $\mathbf{H}^{\prime}$ & D & $\mathbf{E}$ \\
\hline UPS & $12^{\mathrm{a}}$ & $227^{\mathrm{a}}$ & $2.36^{\mathrm{a}}$ & $0.90^{\mathrm{a}}$ & $0.98^{\mathrm{a}}$ \\
\hline $\mathrm{DS}_{2}$ & $7^{\mathrm{b}}$ & $97^{\mathrm{b}}$ & $1.40^{\mathrm{b}}$ & $0.64^{\mathrm{b}}$ & $0.76^{\mathrm{b}}$ \\
\hline CV $(\%)$ & 29 & 7 & 19.35 & 11.42 & 6.17 \\
\hline $\operatorname{MSD}(0.05)$ & 2.98 & 12.52 & 0.40 & 0.097 & 0.052 \\
\hline $\operatorname{SEM}( \pm)$ & 0.95 & 4.02 & 0.13 & 0.03 & 0.02 \\
\hline
\end{tabular}

Note: $\mathrm{F}=$ Total number of Families, $\mathrm{S}=$ Total number of Richness, $\mathrm{H}^{\prime}=$ Shannon-Wiener Diversity Index, $\mathrm{D}=$, Simpson's diversity index E= Equitability or Evenness diversity indices. Means with different letters in the same column are significantly different (Tukey's test at P<0.05) as established by MSD test.

\subsection{Pearson Correlation Matrix (r) Among Selected Physicochemical Parameters and Diversity Indices of Benthos as Biological Indicators of Environmental Flows}

$\mathrm{pH}$ and DO exhibited that they are positively highly significant correlated with diversity indices of benthos, while
BOD and COD have shown negative highly significant correlation with diversity indices of benthos at $(p<0.05)$. Meanwhile, $\mathrm{TN}, \mathrm{NO}_{3}-\mathrm{N}$ and Orth-P has shown a negative correlation with all diversity indices and taxa richness, except evenness at $(p<0.05)$. The richness and all diversity revealed that there is a highly significant dependence on $\mathrm{pH}$ and DO parameters. This suggests that a local increase in $\mathrm{pH}$ and $\mathrm{DO}$ 
was responsible for increase in the richness of benthos.

Table 7. Spearman rank correlations between environmental flow and biological variables determined at sampling sites.

\begin{tabular}{|c|c|c|c|c|c|c|c|c|c|c|c|}
\hline & pH & DO & BOD & COD & TN & $\mathrm{NO}_{3}-\mathrm{N}$ & Orth-P & $\mathbf{S}$ & H' & D & $\mathbf{E}$ \\
\hline $\mathrm{pH}$ & 1.00 & & & & & & & & & & \\
\hline DO & $0.93 * *$ & 1.00 & & & & & & & & & \\
\hline BOD & $-0.94 * *$ & $-0.97 * *$ & 1.00 & & & & & & & & \\
\hline COD & $-0.95 * *$ & $-0.95 * *$ & $0.98 * *$ & 1.00 & & & & & & & \\
\hline $\mathrm{TN}$ & $-0.93 * *$ & $-0.91 * *$ & $0.91 * *$ & $0.94 *$ & 1.00 & & & & & & \\
\hline $\mathrm{NO}_{3}-\mathrm{N}$ & $-0.96 * *$ & $-0.94 * *$ & $0.89 * *$ & $0.90 * *$ & $0.90 * *$ & 1.00 & & & & & \\
\hline Orth-P & $-0.99 * *$ & $-0.91 * *$ & $0.94 * *$ & $0.88 * *$ & $0.81 * *$ & $0.94 * *$ & 1.00 & & & & \\
\hline S & $0.89 * *$ & $0.86 * *$ & $-0.86 * *$ & $-0.80 * *$ & $-0.65^{*}$ & $-0.65^{*}$ & $-0.78 *$ & 1.00 & & & \\
\hline $\mathrm{H}^{\prime}$ & $0.79 * *$ & $0.91 * *$ & $-0.88 * *$ & $-0.85 * *$ & $-0.72 *$ & $-0.69 *$ & $-0.72 *$ & $0.88 * *$ & 1.00 & & \\
\hline $\mathrm{D}$ & $0.77 * *$ & $0.87 * *$ & $-0.88 * *$ & $-0.85 * *$ & $-0.71 *$ & $-0.65^{*}$ & $-0.69^{*}$ & $0.86^{* *}$ & $0.97 * *$ & 1.00 & \\
\hline E & $0.86 * *$ & $0.88 * *$ & $-0.83 * *$ & $-0.81 * *$ & -0.43 & $-0.53 *$ & $-0.60 *$ & $0.75 * *$ & $0.84 * *$ & $0.89 * *$ & 1.00 \\
\hline
\end{tabular}

$* *=$ correlation are highly significant at $\mathrm{p}<0.05$ probability levels, *= Correlation are moderately significant at $\mathrm{p}<0.05$ probability levels and '-' indicate negative correlation. $(\mathrm{E}=$ Equitability or Evenness index, $\mathrm{BOD}=$ Biological Oxygen Demand, $\mathrm{COD}=$ Chemical Oxygen $\mathrm{Demand}, \mathrm{DO}=\mathrm{Dissolved} \mathrm{Oxygen}, \mathrm{D}=$ Simpson's diversity index, $\mathrm{H}^{\prime}=$ Shannon-Wiener Diversity Index, Orth- $\mathrm{P}=$ Orthophosphate, NO3-N= Nitrate nitrogen, $\mathrm{S}=$ Specious richness taxa and TN= Total nitrogen).

\section{Discussion}

A good hydro-ecological integrity of river basin status of sampling sites in the UPS of Limu Kosa District areas were indicated by high proportion of pollution sensitive benthos, whereas, entry point segment receive huge volume of effluents that acts as physical-chemical barrier, which restrict the movement of benthos from $\mathrm{DS}_{2}$ to UPS and vice versa. The results showed that the physicochemical parameter of the effluent discharged from conventional wet washed coffee refineries (CWCR) into the river water (Bonke and Ketalenca river water) decreased slowly toward $\mathrm{DS}_{2}$, while into the river water (Kebena and Awetu river water) alarmingly increased towards $\mathrm{DS}_{2}$. This deterioration of the ecohydrological integrity of freshwater systems river basin quality increases as soon as during the peak time of CWCR time alarmingly increasing rampant discharges into the river basin. The river water bodies located nearby were disrupted by most processing, because CWCR use large quantities of water for fermentation, receiving the cherries, transporting them hydraulically through the pulping machine, removing the pulp, and sorting and re-passing any cherries with residual pulp adhering to them as done by [2-3].

This result indicated that the declining at an alarming and accelerating rate of eco-hydrological system services provision based livelihoods of the people. Due to drawdown river discharge (hypoxia or anoxia) and increased temperatures and reduced water quality in peak time (mid September to mid of December) CWCR, the health of ecosystem is usually at stake in these months, so maintaining ecosystem health and improving biodiversity in such months is more important for water resources planners. This poses a health risk to several rural communities which rely on the receiving water bodies primarily as their sources of domestic water and for other purpose [18].

Benthos assemblages as biological indicators of Eflows were strong positive correlated with $\mathrm{pH}$ and $\mathrm{DO}$, while negative correlations with $\mathrm{BOD}$ and $\mathrm{COD}$ showed that there was low oxygen levels river water bodies nearby CWCR [19].
They also found negative relationship of the mentioned benthos assemblages with variables associated to pollution (turbidity, conductivity, nutrients and total suspended solids) reflected a deterioration of the water quality nearby conventional we coffee refineries [20]. The results can lead to degradation of the level of oxygen in water, which can kill off virtually all aquatic life.

The level of assimilation and removal capacities efficiency of CWCR wastewater treatment systems (lagoon pond) that were intended to serve as effluent outfalls from CWCR from river ecosystem services were very poor. This result indicates that the coffee waste needs much more retention time to stabilize when compared to other organic wastes. This result revealed that conventional lagoon pond (traditionally waste stabilization ponds) is not an eco-friendly waste management option to treat the coffee wastewater effectively. Also the conventional wastewater treatment systems (lagoons) that were intended to serve as assimilation capacity and removal of effluent outfalls from CWCR were properly did not construct nor were they of the right dimension to accommodate the generated effluent during peak time of refineries [2]. Although this fact is widely recognized, lead to overflow of effluents into river water body nearby is a common occurrence. There is need for the intervention of appropriate regulatory agencies to ensure production of high quality treated final effluents by wastewater treatment facilities in rural communities CWCR [3].

\section{Conclusion and recommendation}

The effluents from CWCR are loaded with organic matter and are high in toxicity. The results can lead to degradation of the level of oxygen in river water, which can kill off virtually all aquatic life. High proportion of taxa of benthos assemblages (Ephemeroptera, Hemiptera, Trichoptera, Plecoptera, and Coleoptera) in the UPS as against high pollution tolerant species of families Chironomidae, Simuliidae, and Leeches $\mathrm{DS}_{2}$ were recorded. CWCR effluents having contaminants are intensive incorporated with river water regularly. This study clearly revealed that Eflows were found to be unfit for human consumption and other domestic 
purposes due to the exceeding level of physico-chemical parameters values recommended by $\mathrm{WHO}$ at $\mathrm{DS}_{2}$ of Limu Kosa District. Thus, the challenges to continuous physico-chemical parameters and biological indicators monitoring will be immense. Therefore, urgent intervention in the area of CWCR for effluent management options should be dealt with top priority to avoid further needless damage to the ecohydrological integrity and their development of river water quality using well designed treatment technologies (lagoons) for coffee waste treatment is highly recommended.

\section{References}

[1] Asrat Gebremariam Woldesenbet, Belay Woldeyes, Bhagwan Singh Chandravanshi, 2015. Wet Coffee Processing Waste Management Practice In Ethiopia, Asian J. Sci. Technol., vol. 6, no. 05 , pp. $1467-1471$.

[2] Abebe Beyene, Dejene Yemane, Taffere Addis, A A Assayie, L.Triest, 2014. Experimental evaluation of anaerobic digestion for coffee wastewater treatment and its biomethane recovery potential, Int. J. Environ. Sci. Technol., pp. 1881-1886.

[3] Dejen Yemane, Abebe Beyene, Taffere Addis, Azeb Gebresilassie, 2015.Effect of coffee processing plant effluent on the physicochemical properties of receiving water bodies, Jimma zone Ethiopia, vol. 4, no. 2, pp. 83-90.

[4] Tsigereda Kebede, Metadel Adane, Mekibib David, Fisseha Ittana, 2013. Effectiveness of Advanced Vs Conventional Wet Coffee Processing Technologies in Effluent Wastewater Quality, Int. J. Sci. Eng. Res., vol. 4, no. 8 (2229-5518), pp. 1236-1243.

[5] Asrat Gebremariam, Woldesenbet Belay, Bhagwan Singh, 2014 Characteristics of Wet Coffee Processing Waste and Its Environmental Impact in Ethiopia, Int. J. Res. Eng. Sci., vol. 2, no. 4.

[6] P. M. Ramya, M. Jayasravanthi, B. J. Dulla, and N. R. Venkata, 2015. Chemical Oxygen Demand Reduction From Coffee Processing Waste Water - A Comparative Study on Usage of Biosorbents Prepared From Agricultural Wastes, Global NEST Journal, Vol 17, No 2, pp 291-300.

[7] Asha, G. \& Kumar, B. M., 2016. Performance Evaluation of Sequencing Batch Reactor for Treatment of Coffee Pulping Wastewater, vol. 9 , no. 5, pp. 1-9.

[8] S. Rattan, A. K. Parande, V. D. Nagaraju, and G. K. Ghiwari, 2015. A comprehensive review on utilization of wastewater from coffee processing, Environ. Sci. Pollut. Res., vol. 22, no. 9, pp. 6461-6472.
[9] J. F. Schyns, a. Y. Hoekstra, and M. J. Booij, 2015. Review and classification of indicators of green water availability and scarcity, Hydrol. Earth Syst. Sci. Discuss., vol. 12, no. 6, pp. 5519-5564.

[10] Yared Kassahun, Tesfu Kebede, Fassil Assefa, Aklilu Amasalu, 2011. Environmental impact of coffee processing effluent on the ecological integrity of rivers found in Gomma woreda of Jimma zone, Ethiopia, Ecohydrol. Hydrobiol., vol. 10, no. 2, pp. 259-270.

[11] G. J. Kobingi N, Raburu PhO, Masese FO, 2009. Assessment of pollution impacts on the ecological integrity of the Kisian and Kisat rivers in Lake Victoria drainage basin, Kenya, Afr. J. Environ. Sci Technol., vol. 3 (4):, pp. 097-107.

[12] N.. Akali, N.. Nyongesa, E.. Neyole, and J. B. Miima, 2011. Effluent Discharge by Mumias Sugar Company in Kenya: An Empirical Investigation of the Pollution of River Nzoia, Sacha J. Environ. Stud., vol. 1, no. 1, pp. 1-30.

[13] American Public Health Association (APHA), 2005. Standard Methods for the Examination of Water and Wastewater, 21st ed.; APHA:Washington, DC, USA.

[14] P. B. Niels De Troyer, Seid Tiku Mereta, Peter L.M. Goethals, 2016. Water Quality Assessment of Streams and Wetlands in a Fast Growing East African City, pp. 1-21.

[15] Bouchard, R. W., Jr., 2004. Guide to aquatic macroinvertebrates of the Upper Midwest, Water Resour Center, University of Minnesota, St.Pual, MN. 208 pp.

[16] M. S. Reed, G. Podesta, I. Fazey, N. Geeson, R. Hessel, K. Hubacek, D. Letson, D. Nainggolan, C. Prell, M. G. Rickenbach, C. Ritsema, G. Schwilch, L. C. Stringer, and A. D. Thomas, 2013. Combining analytical frameworks to assess livelihood vulnerability to climate change and analyse adaptation options, Ecol. Econ., vol. 94, pp. 66-77.

[17] D.-S. K. and S.-J. H. Yung-Chul Jun, Nan-Young Kim, Sang-Hun Kim, Young-Seuk Park, 2016. Spatial Distribution of Benthic Macroinvertebrate Assemblages in Relation to Environmental Variables in Korean Nationwide Streams, Water, vol. 8:27, pp. 1-20.

[18] J. O. Walakira P, 2011. Impact of Industrial Effluents on Water Quality of Receiving Streams in Nakawa-Ntinda, Uganda, pp. 289-296.

[19] A. O. Adeogun, T. A. Babatunde, and A. V. Chukwuka, 2012. Spatial and temporal variations in water and sediment quality of Ona river, Ibadan, Southwest Nigeria, Eur. J. Sci. Res., vol. 74, no. 2, pp. 186-204.

[20] M. Mauad, M. L. Miserendino, M. A. Risso, and J. Massaferro, 2015. Assessing the performance of macroinvertebrate metrics in the Challhuaco-Ñireco System (Northern Patagonia, Argentina ), vol. 105, no. 1999, pp. 348-358. 